\title{
Autogenous Tooth Transplantation: Better Way of Replacement: Review and Case Report
}

\author{
Ahmed Khan, Tazeen Fatima, Tehseen Fatima and Parul Tandon*
}

Department of oral \& maxillofacial surgery, Rama dental college, Kanpur (UP), Postal address-43/8, S.P. Marg, Civil Lines, Allahabad, Uttar Pradesh (211001), India

\begin{abstract}
Autotransplantation provides the possibility of a natural tooth rather than a prothesis or an osseointegrated implant to replace a missing tooth. The indications for autotransplantation are wide, but careful patient selection coupled with an appropriate technique is a prerequisite for a good functional and esthetic outcome. Autogenous tooth transplantation is the surgical movement of a tooth from one location in the mouth to another in the same individual. It has achieved high success rates and is an excellent option for tooth replacement. This paper describes the review on autogenous tooth transplantation and also highlights the advantages of autotransplantation using a case report as an example.
\end{abstract}

Keywords: Autotransplantation; Missing teeth; Tooth/ Transplantation; Tooth loss

\section{Introduction}

An edentulous space in an alveolar process can be a challenge to the dental surgeon. There are various options available to replace a missing tooth with removal prosthesis, fixed prosthesis or implants which are often limited by bone availability and are expensive. Tooth transplantation is an excellent alternative for replacing missing teeth as it can serve and function as a normal tooth. Autogenous tooth transplantation or autotransplantation is a surgical movement of a tooth from its original location to another site in the mouth within the same person [1].

Autotransplantation is advantageous as it allows improved masticatory function and esthetics as well as maintaines arch space and volume of alveolar bone. However, several complications, such as root resorption, ankylosis, fracture of donor tooth during extraction can occur [2,3]. The purpose of this article was to present a brief review on autotransplantation and to present a case of successful transplant.

\section{Review}

\section{History}

The earliest reports of tooth transplantation involve slaves in ancient Egypt who were forced to give their teeth to their pharaos [4]. This type of dental surgical intervention was first documented by Abulcassis in 1050; however in 1564, the first recorded surgery with details about tooth bud transplantation was performed by a French dentist Ambroise Pare [5]. In 1915, a Swedish surgeon Vidman described autogenic transplantation of teeth in dental literature [6]. In 1973, Fong reported the successful auto transplantation of $3^{\text {rd }}$ molars [7-9]. In 1954, M. L. Hale well documented autogenous tooth transplantation [10] and was followed by other authors who validated the procedure. Autogenous tooth transplantation is defined as the transfer of a tooth from one position to another in the same individual. This could involve the transfer of impacted, embedded or erupted teeth into extraction sites or into surgically prepared sockets.

\section{The use of the teeth for transplantation is indicated for the} following reasons

In adolescents the first permanent molar may frequently be lost due to excessive carious invasion. In such patients, developing third molars may be considered as a good source for transplantation. Loss of teeth following trauma. The most frequently involved teeth in trauma are maxillary incisors. Zachrisson reported auto transplantation of the developing mandibular second premolar to the avulsed maxillary incisors [11]. In cases of developmental anomalies of teeth and related syndromes such as tooth aplasia [12], cleidocranial dysplasia [13] and tooth agenesis (especially of premolars and lateral incisors) [14]. Patients with ectopic positioned teeth especially canines [15]. Auto transplantation shows benefit in cases of jaw reconstruction after tumor resection [16]. Cervical root fractures ${ }^{15}$. Localised juvenile periodontitis [17-20]. Contraindications-patients with poor oral hygiene, poor self-motivation, unhealthy donor tooth and insufficient width of the receptor bed are the contraindication for autotransplantation. If the recipient site has insufficient alveolar bone support in all dimensions, resorption of the alveolar ridge may ooccur [13].

\section{Factors influencing prognosis of auto transplantation}

Related to donor site: The most important factor which governs the success of transplant is the vitality of periodontal ligament of transplanted tooth. The periodontal ligament is sensitive to $\mathrm{pH}$ changes and its viability is reduced if extra oral time dry is extended. The longer the tooth is left outside the socket, the poorer the prognosis [21]. Andreasen et al reported that extra-alveolar time exceeding $18 \mathrm{~min}$ of a donor tooth affects the survival rate of PDL cells significantly [22-24]. The chances of periodontal ligament healing are greatly increased when a donor tooth is immediately placed into a fresh extraction socket. Preservation of bone and periodontal support following atraumatic surgical technique. Protection of pulpal tissue and Hertwig's root sheath is important as root growth may be compromised leading to ankylosis or root resorption. This can be achieved by minimal handling of the transplant. Correction of any occlusal discrepancy of transplanted tooth, allowing proper healing of the periradicular tissues. Teeth with an open apex have a diminished risk of necrosis and thus shows successful transplantation without the need of endodontic therapy as

${ }^{*}$ Corresponding author: Parul Tandon, Department of oral \& maxillofacial surgery, Rama dental college, Kanpur, Uttar Pradesh, India, Tel: 0702838280; Email: idparul.tandon12@gmail.com

Received September 04, 2015; Accepted November 23, 2015; Published November 30, 2015

Citation: Khan A, Fatima T, Fatima T, Tandon P (2015) Autogenous Tooth Transplantation: Better Way of Replacement: Review and Case report. J Clin Case Rep 5: 642. doi:10.4172/2165-7920.1000642

Copyright: () 2015 Khan A, et al. This is an open-access article distributed under the terms of the Creative Commons Attribution License, which permits unrestricted use, distribution, and reproduction in any medium, provided the original author and source are credited. 
these teeth can be revascularised and reinnervated postoperatively [17]. However, endodontic therapy is always required for transplants of mature teeth with complete root formation. In teeth with closed apex, the pulp of teeth should be extirpated after transplantation, otherwise the necrotic pulp and subsequent infection may result in inflammatory resorption and decreases the survival of transplants [6]. It is reported in the literature that endodontic treatment is not advisable at the time of surgical procedure as it increases the risk of root resorption [13] and also early endodontic treatment may find the tooth with some mobility, which is uncomfortable for the patient as well as for the surgeon [12]. In this case, we have performed the endodontic treatment simultaneously as the root formation was completed with closed apex, it was a single rooted tooth and present in the accessible site of oral cavity. Donor teeth having one-half to two-thirds completed root development shows the most predictable results [18,25-32]. Teeth with less than one-half root formation may prove traumatic while extraction thus compromising the results adequate fixation and stabilization of the transplanted tooth is necessary however, rigid splinting will adversely affect its healing outcome. The splint should not force the tooth against the bony walls of the alveolus as it may damage the periodontium [33]. Adequate flexible splinting of the donor tooth in the recipient allows functional movement of teeth thus stimulating PDL cells activity [23]. The duration of splinting is also very important to take care of It is reported that splinting enhances periodontal healing if kept for 2 weeks to 2 months depending upon the mobility [34]. In our case, splinting was removed after 6 weeks. Closure of the gingival flap around the donor tooth has a paramount importance. There should be tight closure and close adaptation around the transplanted tooth as this enhances reattachment and may block bacterial invasion into the blood clot between the tooth and socket [35].

Related to recipient site: Success of auto transplantation depends upon the adequacy and bone support of the recipient bed. The recipient site should have sufficient alveolar bone support in all dimensions with sufficient attached keratinized tissues to allow tooth stabilization. When bone width is not sufficient bucco-lingually, green stick fracture at the recipient site [36,37],or bone grafting can be performed. Acute infection and chronic inflammation free recipient site [28]. An ideal sequence for auto transplantation is to perform extraction of the tooth from the recipient site on the same day that the donor tooth is removed for transplantation. However, if tooth from the recipient site is extracted earlier due to any reason, the transplantation should be performed within 1 month time interval. As the time interval increases, resorption at the recipient site increases $[36,37]$.

\section{Advantages of autotransplants over FPD'S /implants}

It offers potential benefits such as bone induction and the reestablishment of a normal alveolar process in addition to tooth replacement. Good alternative to fixed prosthetics as it avoids adjacent teeth preparation. Biological and economical treatment alternative for tooth replacement. A transplant maintains natural space with little or no root resorption, alveolar bone volume, and the morphology of alveolar ridge through proprioceptive stimulation [6,38]. May be considered as a temporary option in young patients for replacing missing units. Dental implants are contraindicated in young patients as this procedure causes bone and dental implant material to be fused together, the implant does not erupt along with adjacent teeth. The transplants thus can replace missing teeth along with preservation of the bone until growth has ceased for implants. Time saving as it can be performed as a single step surgical procedure [39]. Transplants have the potential for superior esthetic results since the natural emergence profile and the natural beauty of enamel and crown form is maintained [40]. Can serve and function as a normal tooth.

\section{Case Report}

A 20 years old female patient reported to Dept of OMFS with a chief complaint of missing teeth in lower front region of jaw since birth. clinical examination showed missing 42(right mandibular lateral incisor). A radiograph was taken of that region which revealed impacted 42 (Figure 1). This tooth had root formation completed with mature apices and was suitable for transplantation. Thus autogenous tooth transplantation was suggested in the same region of 42 by surgically preparing a fresh socket to prevent bone resorption and to restore function and esthetics. A complete medical history was taken and an informed consent was obtained after the patient was explained about the treatment protocol including the risks and benefits.

\section{Surgical Procedure}

The procedure was performed as a single stage procedure. A flap was raised to visualize impacted tooth (Figure2). With the help of surgical carbide round bur using a low speed handpiece under copious saline irrigation, the labial cortex was trimmed and 42 was extracted atraumatically (Figure 3). The tooth was then measured to evaluate the accurate dimensions and

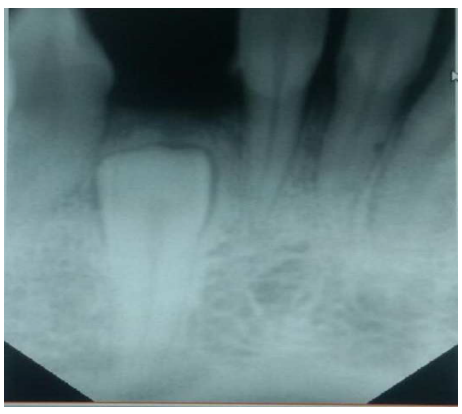

Figure 1: Preoperative X-ray

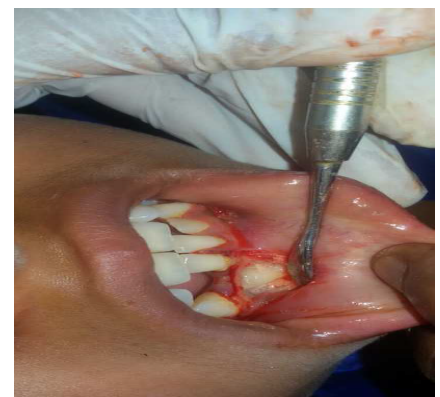

Figure 2: Exposure of the impacted lateral incisor.

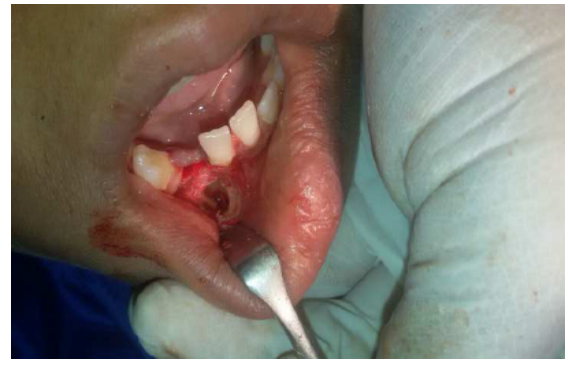

Figure 3: Defect filled with bone graft. 


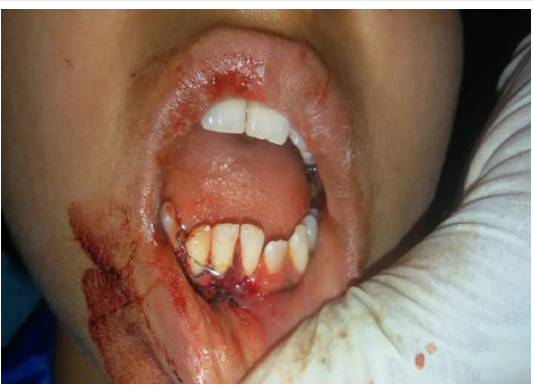

Figure 4: Splinting done.

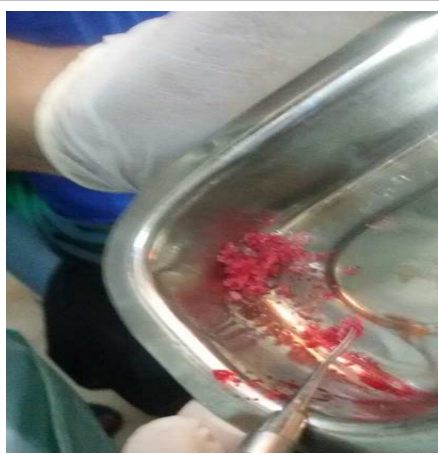

Figure 5: Follow-at 6 week.

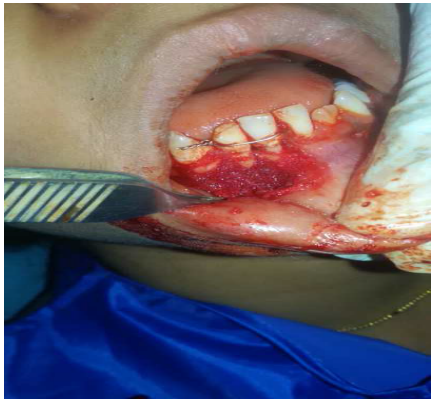

Figure 6: Follow-at 6 months.

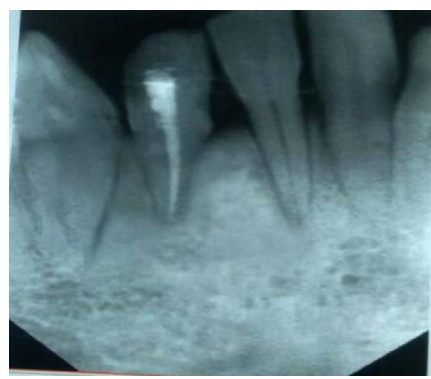

Figure 7: Follow-up at 1 year.

was placed in a normal saline solution. A fresh surgical socket was then prepared according to the measured dimensions and the tooth was then placed into the recipient socket and its fitting was evaluated. Wire splinting was done to stabilize the tooth in the socket (Figure 4). Pulp extirpation was done in 42 ,canal were cleansed, shaped and was filled with gutta percha cones. $5 \mathrm{ml}$ of patients blood was then withdrawn from the anticubital vein and was mixed with calcium hydroxyapatite granules (Figure 5), and was placed in the defect which was created while removing the impacted tooth (Figure 6). This tends to accelerate the process of new bone formation and also gives additional support labially and apically to the transplanted tooth. The flap was sutured back by 3-0 black silk and the occlusal adjustments were made.

\section{Postoperative Care}

Patient was prescribed antibiotics and analgesics for 5 days and $0.12 \%$ chlorhexidine mouthwash twice a day for 2 weeks. The splint was removed at 6 weeks postop. Clinical and radiographic evaluation was done at 2 weeks, 1month, 3 months and 6 month follow-up (Figure 7) showed successful transplantation.

\section{Conclusion}

Autogenous transplantation should be considered as a viable option for treatment of an edentulous space. Although it has not been established as a traditional means of replacing a missing tooth, it warrants more consideration.

\section{References}

1. Leffingwell CM (1980) Autogenous tooth transplantation: a therapeutic alternative. Dent Surv 56: 22-2, 26.

2. Cho JH, Hwang HS, Chang HS, Hwang YC (2013) Application of orthodontic forces prior to autotransplantation - case reports. Int Endod J 46: 187-194.

3. Clokie CM, Yau DM, Chano L (2001) Autogenous tooth transplantation: an alternative to dental implant placement? J Can Dent Assoc 67: 92-96.

4. Natiella JR, Armitage JE, Greene GW (1970) The replantation and transplantation of teeth. A review. Oral Surg Oral Med Oral Pathol 29: 397-419.

5. Nathalia Martins, Daniel Rey, Alexander Franco, Sergio Macedo (2012) Dental autotransplant:case report. RSBO 9: 108-113.

6. Tsukiboshi M (1993) Autogenous tooth transplantation: a reevaluation. Int $J$ Periodontics Restorative Dent 13: 120-149.

7. Bae JH, Choi YH, Cho BH, Kim YK, Kim SG (2010) Autotransplantation of teeth with complete root formation: a case series. J Endod 36: 1422-1426.

8. Akiyama $\mathrm{Y}$, Fukuda $\mathrm{H}$, Hashimoto $\mathrm{K}$ (1998) A clinical and radiographic study of 25 autotransplanted third molars. J Oral Rehabil 25: 640-644.

9. Yan Q, Li B, Long X (2010) Immediate autotransplantation of mandibular third molar in China. Oral Surg Oral Med Oral Pathol Oral Radiol Endod 110: 436440.

10. Hale ML (1956) Autogenous transplants. Oral Surg Oral Med Oral Pathol 9 76-83.

11. Zachrisson BU1 (2008) Planning esthetic treatment after avulsion of maxillary incisors. J Am Dent Assoc 139: 1484-1490.

12. Manuel Marques-Ferreira, Maria-Filomena Rabaça-Botelho, Lina Carvalho Barbara Oliveiros, et al. (2011) Autogenous tooth transplantation: Evaluation of pulp tissue regeneration. Med Oral Patol Oral Cir Bucal 16: e984-989.

13. Thomas S, Turner SR, Sandy JR (1998) Autotransplantation of teeth: is there role? Br J Orthod 25: 275-282.

14. Josefsson E, Brattström V, Tegsjö U, Valerius-Olsson H (1999) Treatment of lower second premolar agenesis by autotransplantation: four-year evaluation of eighty patients. Acta Odontol Scand 57: 111-115.

15. Clokie CM, Yau DM, Chano L (2001) Autogenous tooth transplantation: an alternative to dental implant placement? J Can Dent Assoc 67: 92-96.

16. Landes, Constantin A, Glasl, Bettina, Ludwig, et al. (2008) Tooth Autotransplantation in a Free lliac Crest Graft for Prosthetic Reconstruction. Journal of Craniofacial Surgery 19: 1281-1286

17. Leffingwell CM (1980) Autogenous tooth transplantation: a therapeutic alternative. Dent Surv 56: 22-2, 26.

18. Kahnberg KE1 (1987) Autotransplantation of teeth (I). Indications for transplantation with a follow-up of 51 cases. Int J Oral Maxillofac Surg 16: 577 585 
Citation: Khan A, Fatima T, Fatima T, Tandon P (2015) Autogenous Tooth Transplantation: Better Way of Replacement: Review and Case report. J Clin Case Rep 5: 642. doi:10.4172/2165-7920.1000642

19. Tegsjö U, Valerius-Olsson H, Frykholm A, Olgart K (1987) Clinical evaluation of intra-alveolar transplantation of teeth with cervical root fractures. Swed Dent J 11: $235-250$

20. Kristerson L, Lagerström L (1991) Autotransplantation of teeth in cases with agenesis or traumatic loss of maxillary incisors. Eur J Orthod 13: 486-492.

21. Raghoebar GM, Vissink A (1999) Results of intentional replantation of molars J Oral Maxillofac Surg 57: 240-244.

22. Lee SJ, Jung IY, Lee CY, Choi SY, Kum KY (2001) Clinical application of computer-aided rapid prototyping for tooth transplantation. Dent Traumatol 17: 114-119.

23. Teixeira CS, Pasternak B Jr, Vansan LP, Sousa-Neto MD (2006) Autogenous transplantation of teeth with complete root formation: two case reports. Int Endod J 39: 977-985

24. Andreasen JO (1981) The effect of pulp extirpation or root canal treatment on periodontal healing after replantation of permanent incisors in monkeys. J Endod 7: 245-252.

25. Cohen AS, Shen TC, Pogrel MA (1995) Transplanting teeth successfully: autografts and allografts that work. J Am Dent Assoc 126: 481-485.

26. Lundberg T, Isaksson S (1996) A clinical follow-up study of 278 autotransplanted teeth. Br J Oral Maxillofac Surg 34: 181-185.

27. Kugelberg R, Tegsjö U, Malmgren O (1994) Autotransplantation of 45 teeth to the upper incisor region in adolescents. Swed Dent J 18: 165-172.

28. Northway WM, Konigsberg S (1980) Autogenic tooth transplantation. The "state of the art". Am J Orthod 77: 146-162.

29. Pogrel MA (1987) Evaluation of over 400 autogenous tooth transplants. J Oral
Maxillofac Surg 45: 205-211.

30. Akiyama $Y$, Fukuda $\mathrm{H}$, Hashimoto $\mathrm{K}$ (1998) A clinical and radiographic study of 25 autotransplanted third molars. J Oral Rehabil 25: 640-644.

31. Robinson PJ, Grossman LI (1980) Tooth Transplantation. In: Robinson PJ, Guernsey LJ, eds. Clinical transplantation in dental specialties. 77-88.

32. Schwartz O, Bergmann P, Klausen B (1985) Autotransplantation of human teeth. A life-table analysis of prognostic factors. Int J Oral Surg 14: 245-258.

33. Akiyama $Y$, Fukuda $H$, Hashimoto $K$ (1998) A clinical and radiographic study of 25 autotransplanted third molars. J Oral Rehabil 25: 640-644.

34. Tsukiboshi M (2002) Autotransplantation of teeth: requirements for predictable success. Dent Traumatol 18: 157-180.

35. Farheen Ustad, Fareedi Mukram Ali, Zaheer Kota, Abdelbagi Mustafa, Mohd Inayatullah Khan (2011) Autotransplantation of teeth: A Review. Am. J. Med. Dent. Sci 1: 25-30

36. Tsukiboshi M (2001) Autotransplantation of teeth. Quintessence 10-18.

37. Andreasen JO (1992) Atlas of replantation and transplantation of teeth. W.B. Saunders, Philadelphia 58-288.

38. Hernandez SL, Cuestas-Carnero R (1988) Autogenic tooth transplantation: a report of ten cases. J Oral Maxillofac Surg 46: 1051-1055.

39. Asgary S, Ehsani S (2011) Autotransplantation of A Third Molar with Complete Root Development: A Case Report. International Journal of Surgical Research 1: $1-6$.

40. Unni KN, Singh VPP (2012) Autotransplantation of teeth - An overview. Amrita Journal of Medicine 8: 1-44. 